\title{
Development of an Asynchronous Web Based E-Learning System
}

\author{
Nathaniel Olufisayo Oluwaniyi, Babajide Olakunle Afeni, Olusegun Olayinka Lawal \\ Department of Computer Science, Joseph Ayo Babalola University (JABU), Ikeji-Arakeji, Nigeria \\ Email: oluwaniyinathaniel@gmail.com, babajideafeni@gmail.com, oilsla314@gmail.com
}

Received 12 November 2015; accepted 24 December 2015; published 28 December 2015

Copyright (C) 2015 by authors and Scientific Research Publishing Inc.

This work is licensed under the Creative Commons Attribution International License (CC BY). http://creativecommons.org/licenses/by/4.0/

(c) (i) Open Access

\begin{abstract}
Advancements in Information Communication Technology (ICT) have led to several opportunities especially the ones provided by the Internet. Several people are now taking advantage of distance learning courses and in the past few years huge research efforts have been dedicated to the development of distance learning systems. So far, many e-learning systems are proposed and used practically. This paper focused on the development of an asynchronous and interactive Web-based e-learning system. Its primary objective is to develop a fast, reliable, effective and efficient webbased e-learning system that will address the problems associated with the traditional learning system. Succinctly, the paper discusses the design of a system that enhances e-learning where course lecturers can set their courses, tests and quizzes at their convenient time and can track the activities and performance of their students and guide them to acquire knowledge without being obliged to be physically present on the institution campus. The system was designed using PHP as the scripting language, Macromedia Dreamweaver for the web page, MySQL as the database and Apache as the web server. The system was implemented using real data and the result was successful. This system is no doubt a solution to the constraints of the classical learning system and can be used successfully in distance learning, training, and various educational institutions.
\end{abstract}

\section{Keywords}

E-Learning, Web-Based, Asynchronous, Information Communication Technology (ICT)

\section{Introduction}

The Internet has profoundly changed the way we communicate and interact with one another. Studies conducted by Pew Internet and American Life Project found that as of June 2005, 137 million Americans (or 68\% of American adults) used the Internet, up from 63\% one year ago [1]. About 94 million Americans used the Internet 
for such daily activities as e-mailing, searching for information, getting news, checking the weather, instant messaging, and online banking, to name a few [2]. According to [3], the Internet has brought dramatic changes to education. The educational use of computers has evolved from numerical calculations, spreadsheets, and word processors to multimedia and web-based applications. The introduction of the Intranet/Internet access in institutions of learning and organizations has encouraged the development of new mediums and systems within the scope of education and training. Due to the opportunities provided by the Internet, more and more people are taking advantage of distance learning courses [4]. As a result, in a new era, learning and training approaches have emerged, where students can learn independently at any time and from any location, simply by using their computers connected to the net along with the appropriate systems and tools. Teachers also can teach from on-line location and can schedule their lectures and examination without the classical physical constraints. This electronic learning approach known also as e-learning, has opened new horizons in teaching for both teachers and students. E-learning is a general term used to refer to a form of learning in which the instructor and student are separated by space or time where the gap between the two is bridged through the use of online technologies. An e-learning system is a powerful integrated system that supports a number of activities performed by teachers and students during the e-learning process. A web-based asynchronous e-learning system allows educators to develop web-based course notes, test and examination, to communicate with students and to monitor their progress. Students engage the system fort for learning, communication and collaboration. It is important to note that the effectiveness of an e-learner's experience is greatly enhanced through student-centered design. For example, students remember more information from a textbook that is well organized, with extensive visuals, reflection/ interaction points, clear headings, etc. The same concept exists for online courses-learners learn better through use of clear headings, limited distracters, visuals, screen-friendly fonts, appropriate white space, web safe colors, etc. This work developed, implemented and proposed a simple web-based asynchronous e-learning system, in which educators can set teach and also assess their students in form of quizzes and exams. The system will allow educators to store, update, and delete questions from the database using the web, in a very easy and simplified manner. Also, they will be able to track the activities of their students and can guide them to reach the predetermined objectives of the courses.

\subsection{Statement of Problem}

Learning is commonly defined as a process that brings together cognitive, emotional, and environmental influences and experiences for acquiring, enhancing, or making changes in one's knowledge, skills, values, and world views. It is the process of gaining knowledge or skill by reading and studying, from experience, from being taught, etc. Learning system refers to the method or way of impacting knowledge. The two main types of learning system are identified in the educational sector:

- The Classical (Traditional) Learning system: Classical learning system refers to long-established customs found in schools that society has traditionally deemed appropriate. In a traditional learning system, the teacher will talk about one subject for a set amount of time and the students listen to him.

- The E-learning system: E-learning systems are integrated systems that support the delivery of a learning, training or education program by electronic means. It involves the use of a computer or electronic device in some way to provide training, educational or learning material.

Constraints of the classical learning system include:

1) Time: Learners are bound to a specific day/time to physically attend classes.

2) Travel Considerations: A considerable amount of time allocated to attending campus, travel time and risk of life, and travel expenses. Also, students must physically attend the courses to get credit for attendance and when combined with the cost of education, may present an issue to financially challenged students.

3) Overcrowding in Classrooms: Learning no longer become effective when there is overcrowding in classrooms resulting in unnecessary noise and distraction, inconveniences, and lack of concentration.

\subsection{Objectives}

The primary objective of this research is to us Php and Mysql to develop a fast, reliable, effective and efficient web-based e-learning system that will address the problems associated with the traditional learning system. Other objectives are to:

a) Develop a web-based e-learning system; 
b) Implement the system in (a) above

\section{Literature Review}

\subsection{The Evolution of E-Learning}

As stated in [5], people in the field of e-learning began to realize that you simply cannot put information on the web without a learning strategy for the users. In order for technology to impact positively on learning, it must fit into students live and not the other way round. As a result, e-learning was born. A few years ago, teaching and training was not done in front of a computer, but in the classroom. As technology improved, establishments began to integrate training with the computer and the field of e-learning began to take shape. In the early 1990s, many establishments were using videotape-based training for their employees [6].

The work of [7] proposed the architecture for an integrated virtual classroom for delivering lectures, issuing and controlling assignments, with chatting, choices and forums which takes cognisance of e-learning features such as the White board, Audio and Video features. The Video feature enables one to transmit and receive video broadcasts with others in a classroom session.

The idea of putting training on video was a good idea, though it was lacking in a few areas such as: customization based on needs of users, expensive to maintain and uneasy upgrading. These videos often had limited interactions which lead to the nearly impossible task of tracking progress and assessment [8].

Since it was obvious that video was not the best solution, a new form of training evolved, CBT or Computer Based Training. "Windows 3.1, Macintosh, CD-ROMs, PowerPoint marked the technological advancement of the Multimedia Era" [9] CD-ROMs could be cheaply produced so that the problem of checking in and out videos was eliminated. Employees were also able to simply pop in a CD to their personal computer at their desk and complete the training. Although the CD-ROM Computer-Based Training made good advancement, it still lacked the ability to track employees' performance in a central database and was also not as easy to upgrade. All these problems would disappear with the use of the Internet as a means of delivering content. The problem was, when the content was placed on the web, it was simply text to begin with and maybe a few graphics. No one really cared about the effectiveness of this new medium - it was just really according to Cooke, 2004.

One of the first innovations in actual e-learning was the LMS or Learning Management System. The first Learning Management Systems (LMS) offered off-the-shelf platforms for front-end registration and course cataloging, and they tracked skills management and reporting on the back-end [5]. This enabled schools and companies to place courses online and be able to track students' progress, communicate with students effectively and provide a place for real-time discussions. E-learning has come a very long way since its early days of being textbased via the Web or CD-ROM. So what does the future hold? There really is no saying where the field is headed. As long as training is continually geared towards the learners and strategies are used in the training, there is no end in sight for e-learning [10].

\subsection{Technological Limitations of E-Learning}

Students need necessary hardware for e-learning such as desktop or notebook computers and printers. Therefore, one of the major technological limitations of e-learning is the necessity of computer hardware and relevant resources. According to [11], the lack of hardware to support e-learning in organizations is one of the factors why Small and Medium Enterprises are not willing to engage in e-learning to educate its employees. Hardware and other ICT resources are necessary for e-learning implementation in institutions. The Vietnam government spent large sums of money in buying ICT hardware for a college that implemented e-learning [12]. This work of [13] emphasized that in order to participate in online learning, both learners and staff need to have access to networked computers.

\subsection{Personal Issues}

As stated in [14] that preparation is indeed needed for newcomers as they may think that nontraditional learning such as e-learning is the same as a traditional learning environment. Besides, [15] specified that newcomers to nontraditional learning may get lost because they do not know what to do as there is no detailed guidance from the teacher. According to [14], these newcomers need some orientation courses in order for them to get used to a nontraditional learning environment like e-learning. Therefore, it is not surprising to see newcomers needing to 
be psychologically prepared for the e-learning environment. It was mentioned in [16] that the lack of ICT skills is one of the barriers in e-learning training. As e-learning is the product of the advanced technology, e-learners will have to learn new skills and responsibilities related to the technology. According to [17], technical skills could cause frustration to e-learning students due to the unconventional e-learning environment and isolation from others. Consequently, having to learn new technologies may be a barrier or disadvantage in e-learning for ICT novices. E-learning is not an easy task for many as it requires a lot of self-discipline.

\subsection{Limitations of E-Learning System Compared to Traditional Learning System}

Lacking physical interaction is another limitation in e-learning. The work of [18] expressed that the lack of physical interactions made e-learning students feel isolated and apprehensive. Lacking physical interaction may also affect the completion rate. From the work of [19], it was revealed out that half of the students for an Advance Diploma in Education from the University of Ulster commented that it was rather hard to seek advice, as compared to face-to-face instruction. Physical classrooms however will enable learners to learn faster, as they can always refer to the instructors or peers for guidance. Body language is absent in e-learning. An example is when a student stated that he missed "facial and hand gestures", from which important cues can be derived [20]. The lack of physical interactions shown above will hinder the learning process as pointed out by [21], that the omission of observation of student emotions may prevent professors or instructors from responding to student's needs.

Apart from this lack of physical interaction, e-learning is also criticized for not having facilities like traditional campuses: internship, volunteer opportunities, access to physical library, book stores, career and development counseling. Some learning institutions tried to provide these facilities but they were too limited [20]. He further pointed out problems such as budget, compatibility of software, and college policies that hindered the development of integrated supporting systems.

E-learning may not be suitable for certain groups of learners, especially science students who need extensive physical science laboratory experiment. UCLA's School of Dentistry spent around US $\$ 750,000$ to develop their online courseware but later found out that the prospective customers would rather spend more for traditional classroom-based lectures. This may be due to the fact that these students need to carry out a lot of laboratory experiments in order to deepen their skills and knowledge, and this may be hard to achieve through e-learning laboratory simulations.

Difficulty in teaching in an e-learning environment is another issue, as instructors may not be able to teach well. Moving into e-learning is difficult for instructors who are already familiar with the traditional teaching environment. This is because the e-learning teaching environment is new and the e-learning technologies are developing and changing rapidly.

\subsection{Design Limitations}

Poor design of the e-learning courseware is a major issue for learners and e-learning providers, as pointed out by [21]. A poor design "gave users a feeling of being stressed and badly treated by the system". They further said this causes users to feel frustrated and eventually stop learning. Courseware design should be tailored to the needs of the learners: it should be easy to use and students should have easy access to guidance and information. According to [22] it was stated that designing the e-learning courseware is very demanding, as it should not be limited to just content and should include other components to enhance learning. In a nutshell, the poor usability of the online course will inhibit the learner's ability to acquire knowledge.

\subsection{Limitations A Web-Based E-Learning System Experiment}

In the work of [23], they proposed a simple and easy to use e-learning system that is used currently in Qatar University by both students and teachers of the department of Computer Science and Engineering. The system is fully web-based and can run on any platform and compatible with most known browsers. In addition to its ability to manage electronic tutorials, the system uses an intelligent algorithm to generate quizzes and exams with different levels of difficulties according to the desire of the potential users. This algorithm adjusts the pre-set difficulty levels of the questions based on the feedback of the students. The students can see the solutions of 
their exams along with their marks immediately after submitting their answerers. The system reduces the constraints of the classical education system and save time and resources. In fact, teachers can set their courses, exams and quizzes at their convenient time and can track the activities of their students and guide them to acquire correctly the requested knowledge without be obliged to be physically in the university campus.

Similarly, the students can use the system freely and independently from their labs and home through the web. A discussion tool is also provided to allow teachers and students to interact together at a specific time. A bulletin board is also used to make some announcements to students about their courses and quizzes and exams. A questionnaire was prepared and distributed to the potential students registered in the system to obtain some feedback about the Web Based Training (WBT) and quizzes proposed by their system. Sixty students have been randomly selected to use as a testing pool. A group of 30 students have used the hard paper exam and another similar group has used the on-line system. Students had to obtain a grade of $60 \%$ to pass the quiz. After taking the quiz, all the students had to fill in a questionnaire with general and specific questions related to the method of testing. Finally, the majority of the students trust more a computer-based evaluation system than classical methods. Some students did comment on the absence of printed copies of their answers and the fact that they could not compare their answers with the correct results after the quiz [23].

\section{System Methodology}

The proposed system is a web application which will give learners the advantage of learning independently from any location at any time. Through a web interface, students will be able to not only learn the lessons anywhere at any time but also practice at leisure pace, thus overcoming the limitation imposed by time and space. They can also pause learning sessions at their convenience. Students can learn even at home without travelling to take lectures. With the use of a web-based e-learning system, student can learn from any location, simply by using their computers connected to the net along with the appropriate systems and tools. The system will be designed such that teachers can add, update and delete course materials using the web without being physically present at the learning center. The web-based e-learning system will allow students to learn independently at any time and from any location. Therefore, there is no limit to the number of students that can be taught at a time. Students can also view the result of a quiz, practice question, etc, after each test independent of the number of students involved.

\subsection{Proposed Design of the E-Learning Platform}

The system interface is entirely web-based, and is fully compatible with almost all well-known browsers. The system environment consist of the following: The first one is the client side application, which was developed with HTML and JavaScript. The second is the server program, which was developed with PHP. PHP acts as a gateway between the database and the clients. Lastly, the database management system (DBMS) which keeps and classifies all the questions is Mysql. Mysql is a relational database system. It uses Structured Query Language which is the most common database language. MySQL content can be managed via a command line or a web interface. It is open source and therefore free.

\subsection{Data Flow Diagram (DFD) of the Proposed System}

Data flow diagrams (Figures 1-3) define the functionality of a system. It describes the source from which data is coming, the change that occurs in the system and the source at which it ends. It is a representation of data flow through a system during which it is processed as well.

\subsection{Database Table Design}

Below are the table names that were created during the development of the system and their attributes.

\subsubsection{Add Lessons}

Table 1 stores the details of any lesson that will be added by a lecturer using the system

\subsubsection{Administrator}

Table 2 stores the details of an administrator. 


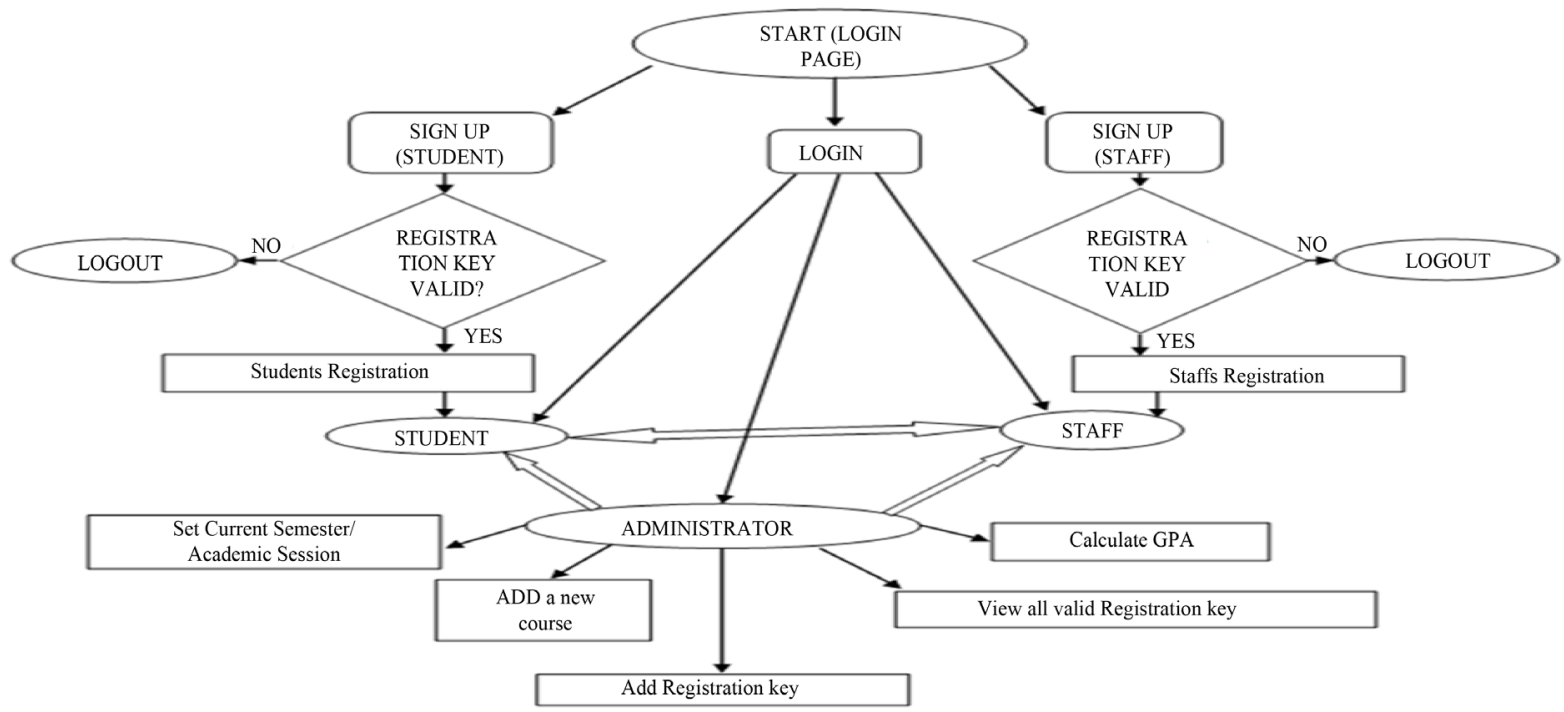

Figure 1. DFD 1 of the web-based e-learning system.

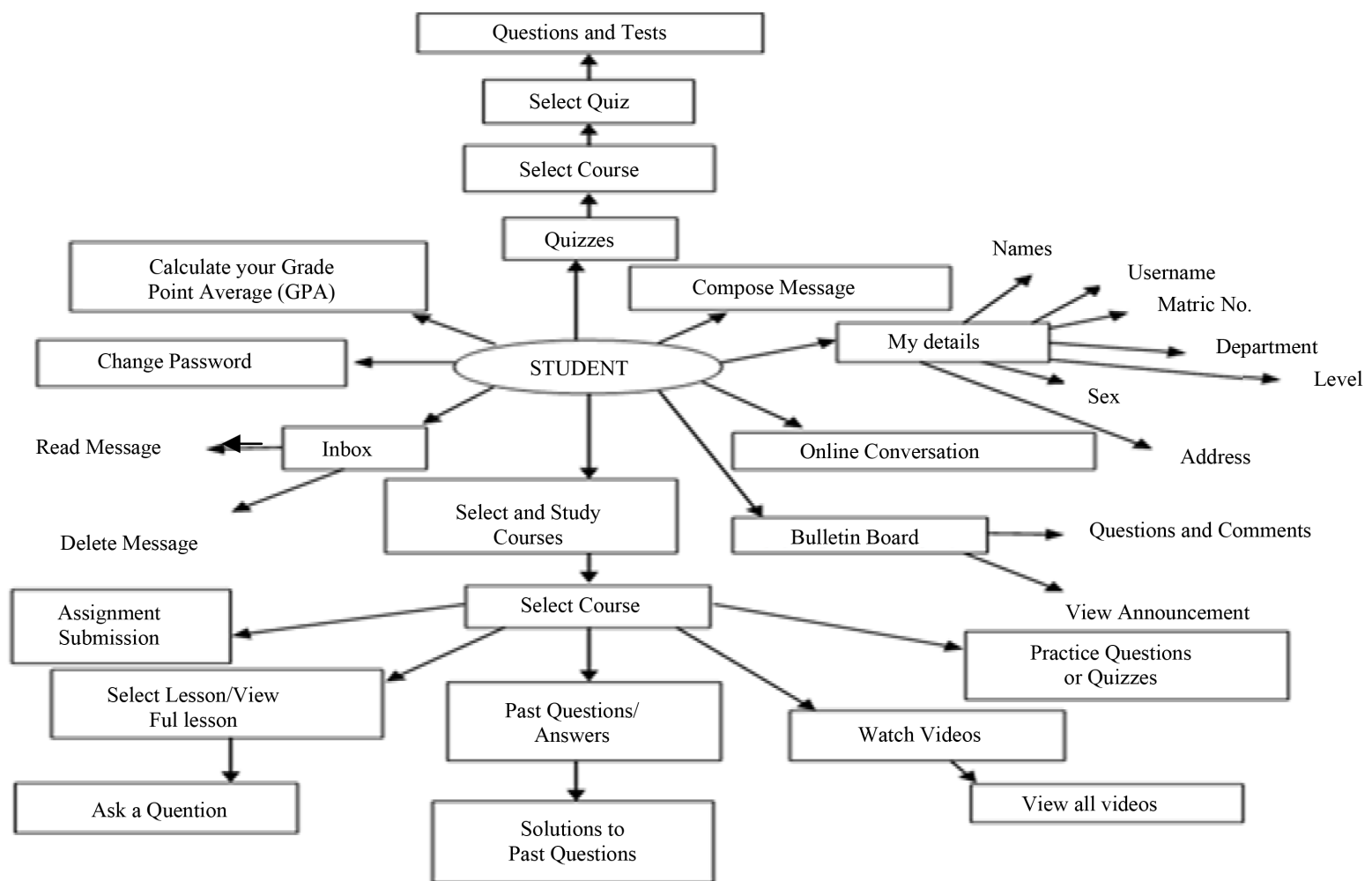

Figure 2. DFD 2 of the web-based e-learning system.

\subsubsection{Administrator Check}

Table 3 stores the changes made by an administrator. The administrator sets the current semester and academic session.

\subsubsection{All Courses}

Table 4 consists of all the courses offered in the department; the course code, course title, units and the level in which each course is taken. 


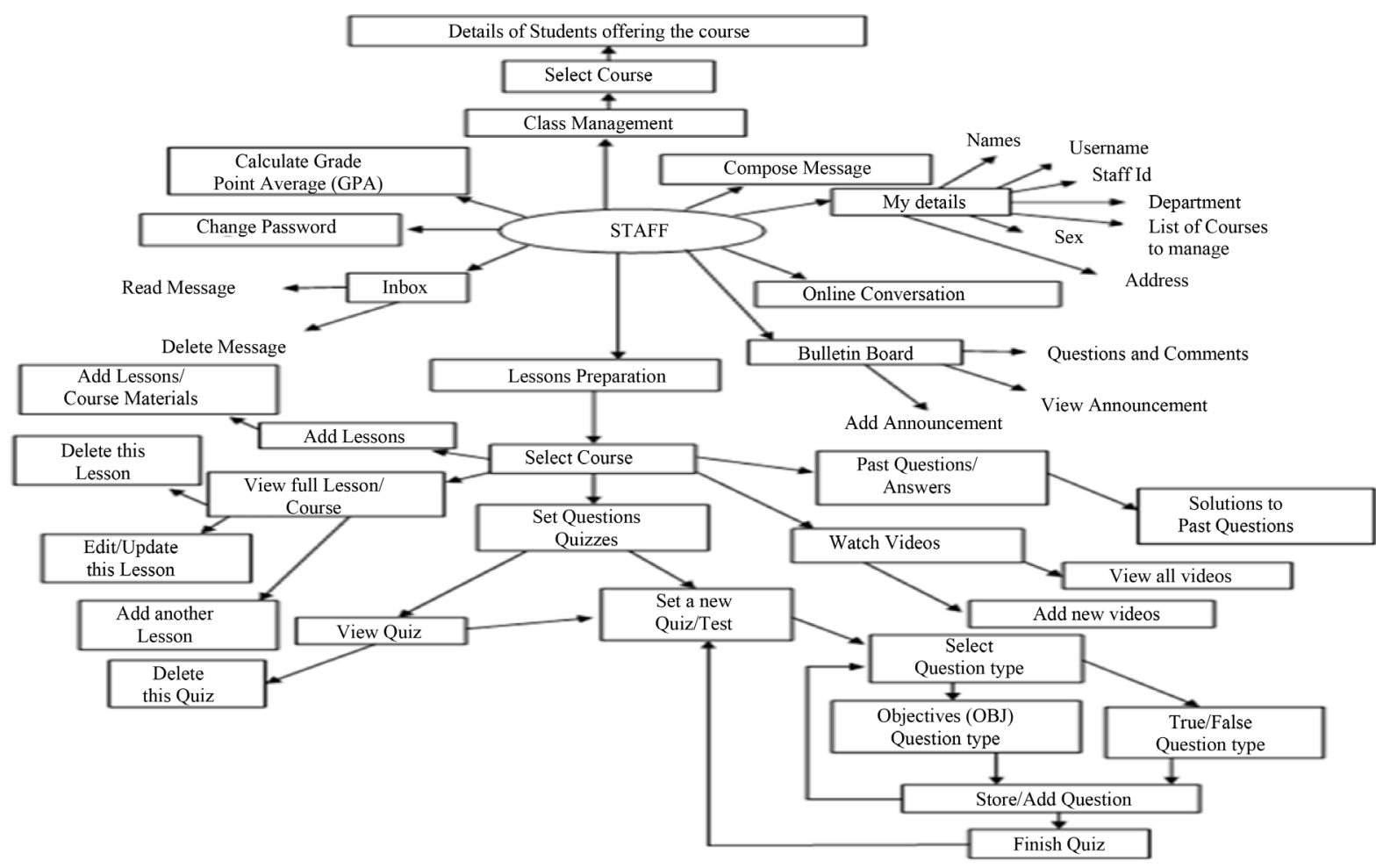

Figure 3. DFD 3 of the web-based e-learning system.

Table 1. Add lessons table.

\begin{tabular}{ccccc}
\hline Column Name & Primary key & Data type & NOT NULL & AUTO INC \\
\hline ID & Yes & INTEGER & Yes & Yes \\
Course code & & VARCHAR (45) & Yes & \\
Course title & VARCHAR (450) & Yes \\
Units & INTEGER & Yes & Yes \\
Lecturer & VARCHAR (450) & Yes & Yes \\
Topic & TEXT & Yes \\
Lesson & TEXT & BLOB & \\
File & &
\end{tabular}

Table 2. Administrator table.

\begin{tabular}{ccccc}
\hline Column Name & Primary key & Data type & NOT NULL & AUTO INC \\
\hline ID & Yes & INTEGER & Yes & Yes \\
Username & & VARCHAR (45) & Yes & \\
Password & & VARCHAR (45) & Yes & \\
First name & & VARCHAR (45) & Yes & \\
\hline
\end{tabular}

Table 3. Administrator check table.

\begin{tabular}{ccccc}
\hline Column Name & Primary key & Data type & NOT NULL & YUTO INC \\
\hline ID & Yes & INTEGER & Yes \\
Semester & & VARCHAR(45) & Yes \\
Academic session & & VARCHAR(45) \\
\hline
\end{tabular}


Table 4. All courses table.

\begin{tabular}{ccccc}
\hline Column Name & Primary key & Data type & NOT NULL & AUTO INC \\
\hline ID & Yes & INTEGER & Yes & Yes \\
Course code & & VARCHAR (45) & Yes & \\
Course title & & VARCHAR (4500) & Yes \\
Units & & INTEGER & Yes \\
Level & & INTEGER & Yes \\
Semester & & VARCHAR (45) & Yes \\
\hline
\end{tabular}

\subsubsection{Lecturer Course}

Table 5 stores the username of any teacher/staff managing a particular course.

Table 5. Lecturers course table.

\begin{tabular}{ccccc}
\hline Column Name & Primary key & Data type & NOT NULL & AUTO INC \\
\hline ID & Yes & INTEGER & Yes \\
Username & & VARCHAR (45) & Yes \\
Course code & & VARCHAR (45) & \\
\hline
\end{tabular}

\subsubsection{Login}

The login Table 6 stores the details of a student during his/her registration.

Table 6. Login table.

\begin{tabular}{|c|c|c|c|c|}
\hline Column Name & Primary key & Data type & NOT NULL & AUTO INC \\
\hline ID & Yes & INTEGER & Yes & Yes \\
\hline Username & & VARCHAR (45) & Yes & \\
\hline Password & & VARCHAR (45) & Yes & \\
\hline First name & & VARCHAR (45) & Yes & \\
\hline Middle name & & VARCHAR (45) & Yes & \\
\hline Last name & & VARCHAR (45) & Yes & \\
\hline Department & & VARCHAR (45) & Yes & \\
\hline Level & & VARCHAR (45) & Yes & \\
\hline Address & & VARCHAR (4500) & Yes & \\
\hline Sex & & VARCHAR (45) & Yes & \\
\hline Matric No. & & VARCHAR (45) & Yes & \\
\hline
\end{tabular}

\subsubsection{Message}

Table 7 stores all the messages sent by those using the system along with the recipient username and names of the sender.

Table 7. Massage table.

\begin{tabular}{ccccc}
\hline Column Name & Primary key & Data type & NOT NULL & Yes \\
ID & Yes & INTEGER & Yes & Yes \\
Username & & VARCHAR (45) & Yes \\
Status & & VARCHAR (45) & Yes \\
First name & VARCHAR (45) & Yes \\
Last name & VARCHAR (45) & Yes \\
subject & VARCHAR (60) & Yes \\
Main body & & VARCHAR (5000) & \\
\hline
\end{tabular}




\subsubsection{Registration Key}

The registration key Table 8 stores all valid registration keys and changes the value of the status if a particular key had been used.

Table 8. Registration key table.

\begin{tabular}{ccccc}
\hline Column Name & Primary key & Data type & NOT NULL & AUTO INC \\
\hline ID registration key & Yes & INTEGER & Yes & Yes \\
Reg1 & & VARCHAR (45) & Yes & \\
Status & & VARCHAR (45) & Yes & \\
\hline
\end{tabular}

\subsubsection{Set Question}

Table 9 stores the questions and quizzes set by staffs/teachers.

Table 9. Set question table.

\begin{tabular}{ccccc}
\hline Column Name & Primary key & Data type & NOT NULL \\
\hline Id & Yes & INTEGER & Yes & Yes \\
Course code & & VARCHAR (45) & Yes \\
Quiz what & & VARCHAR (45) & Yes \\
Question & VARCHAR (5000) & Yes \\
A & VARCHAR (5000) & Yes \\
B & VARCHAR (5000) & Yes \\
C & & VARCHAR (5000) & Yes \\
D & & VARCHAR (5000) & Yes \\
\hline
\end{tabular}

\subsubsection{Staff Login}

The staff login Table 10 stores the details of a staff during his/her registration.

Table 10. Staff login table.

\begin{tabular}{|c|c|c|c|c|}
\hline Column Name & Primary key & Data type & NOT NULL & AUTO INC \\
\hline ID & Yes & INTEGER & Yes & Yes \\
\hline Username & & VARCHAR (45) & Yes & \\
\hline Password & & VARCHAR (45) & Yes & \\
\hline First name & & VARCHAR 45) & Yes & \\
\hline Middle name & & VARCHAR (45) & Yes & \\
\hline Last name & & VARCHAR (45) & Yes & \\
\hline Title & & VARCHAR (45) & Yes & \\
\hline Department & & VARCHAR (45) & Yes & \\
\hline Address & & VARCHAR (4500) & Yes & \\
\hline Sex & & VARCHAR (45) & Yes & \\
\hline
\end{tabular}

\section{System Design and Implementation}

Macromedia Dreamweaver was used in the design of the web pages, PHP (Hypertext Preprocessor) as the scripting language, MySQL serve as the database and Apache as the web server. Since it is a web-based application, to implement the system, the website has to be hosted to make it accessible online.

\subsection{Development Tools}

The development tools used are: 
- HTML (Hypertext Markup Language)

- PHP (Hypertext Preprocessor)

- Javascript

- CSS (Cascading Style Sheets)

- MySQL (RDBMS)

\subsection{System Requirements}

The system requirements are classified into two:

- Hardware requirements

- Software requirements

\subsubsection{Hardware Requirements}

The following are the minimum computer hardware requirements for effective running of the web-application:

- A full computer system (keyboard, mouse and monitor)

- Minimum of 512 MB RAM

- Minimum of 50 GB hard disk size

- Minimum of $1.60 \mathrm{GHz}$ Processor speed

- An Uninterrupted Power Supply (UPS)

- A stabilizer

\subsubsection{Software Requirements}

For this web-application to function efficiently, the following software needs to be running on the computer system:

- A Wamp server/Apache server

- A web browser (Mozilla Firefox, Google Chrome, Internet Explorer etc)

- Relational Database Management System (RDBMS): MySQL.

\subsection{Using the Web-Based E-Learning System}

\subsubsection{Login Page}

On the login page shown in Figure 4, you can login to the system as a student, staff or an administrator depending on your username and password. On that same page (the login page), you can sign up as a student or staff if you are a new user.

\subsubsection{Students Home Page}

This page shows the home page for a student who had logged into the system (see Figure 5).

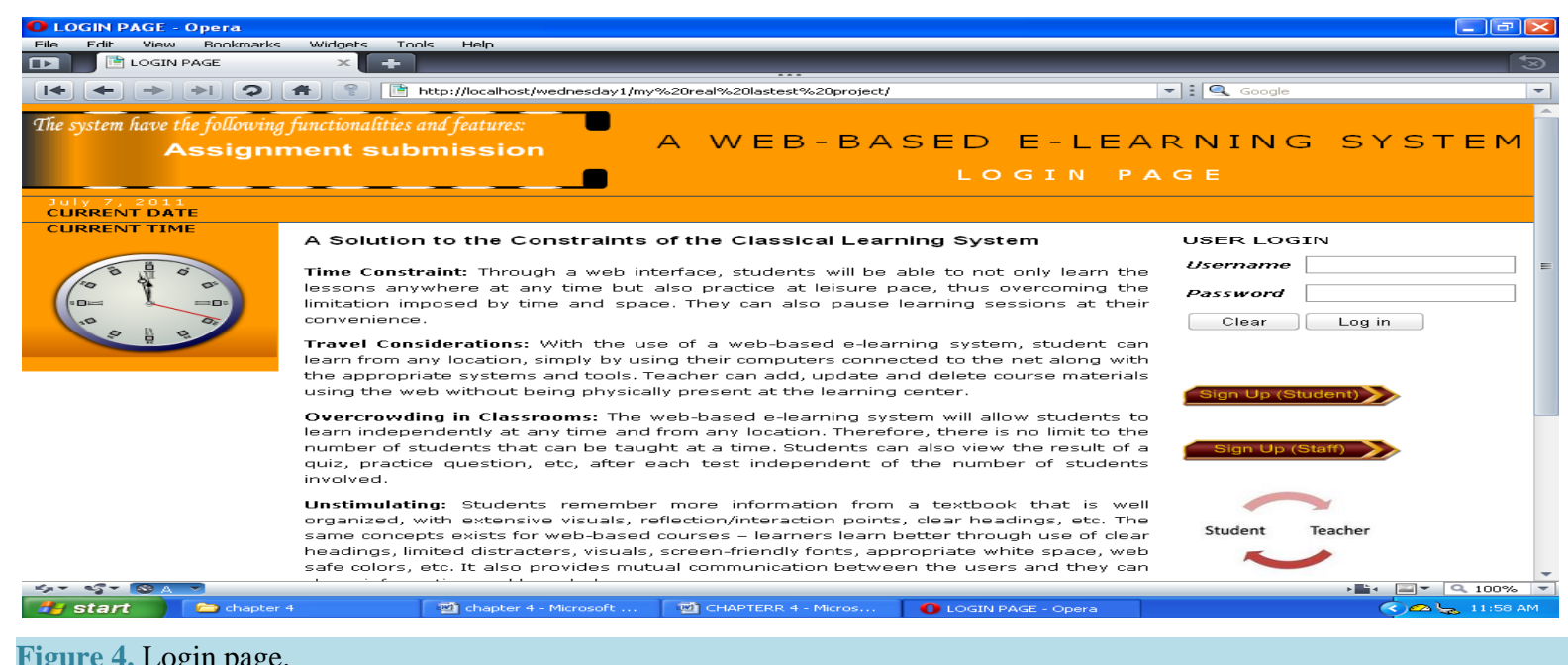

Figure 4. Login page. 


\subsubsection{Staff Home Page}

This shows (Figure 6) the home page for a staff who had just logged into the system.

\subsubsection{My Details Page}

Here, both staffs and students will be able to view their personal details. The details include: Names, Matric no, Department, Sex, Level, Username, Address, etc. Staffs are also able to see the list of course they are managing.

\subsubsection{Inbox Page}

On this page (Figure 7), staffs and students can check messages sent to them by their colleagues and friends. Staffs can send message to students and vice-versa. Unread messages are bold compared to those ones that have been read.

\subsubsection{Inbox (Message)}

This page (Figure 8) allows users (staffs and students) to read the body of the message sent to them.

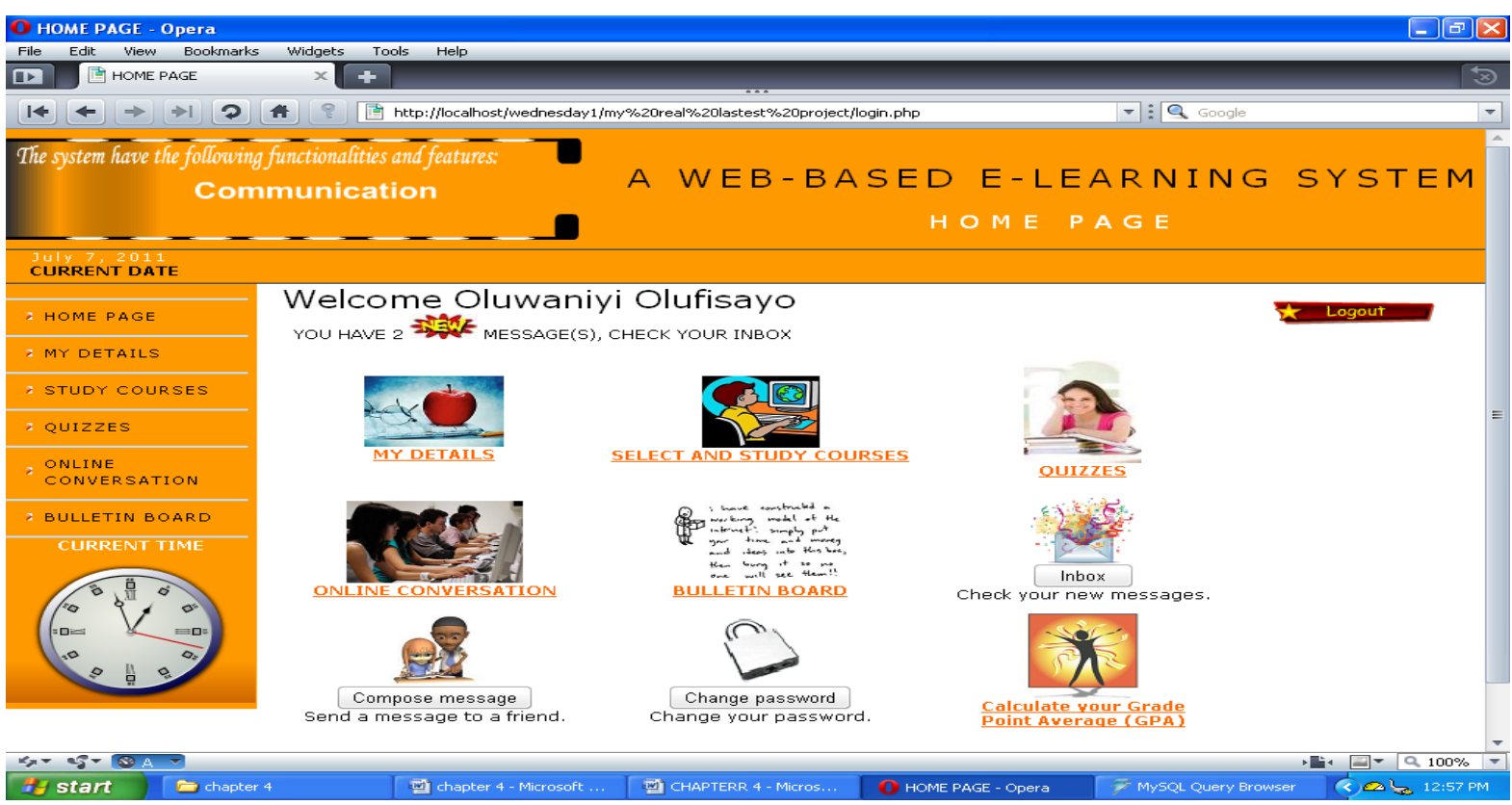

Figure 5. Student home page.

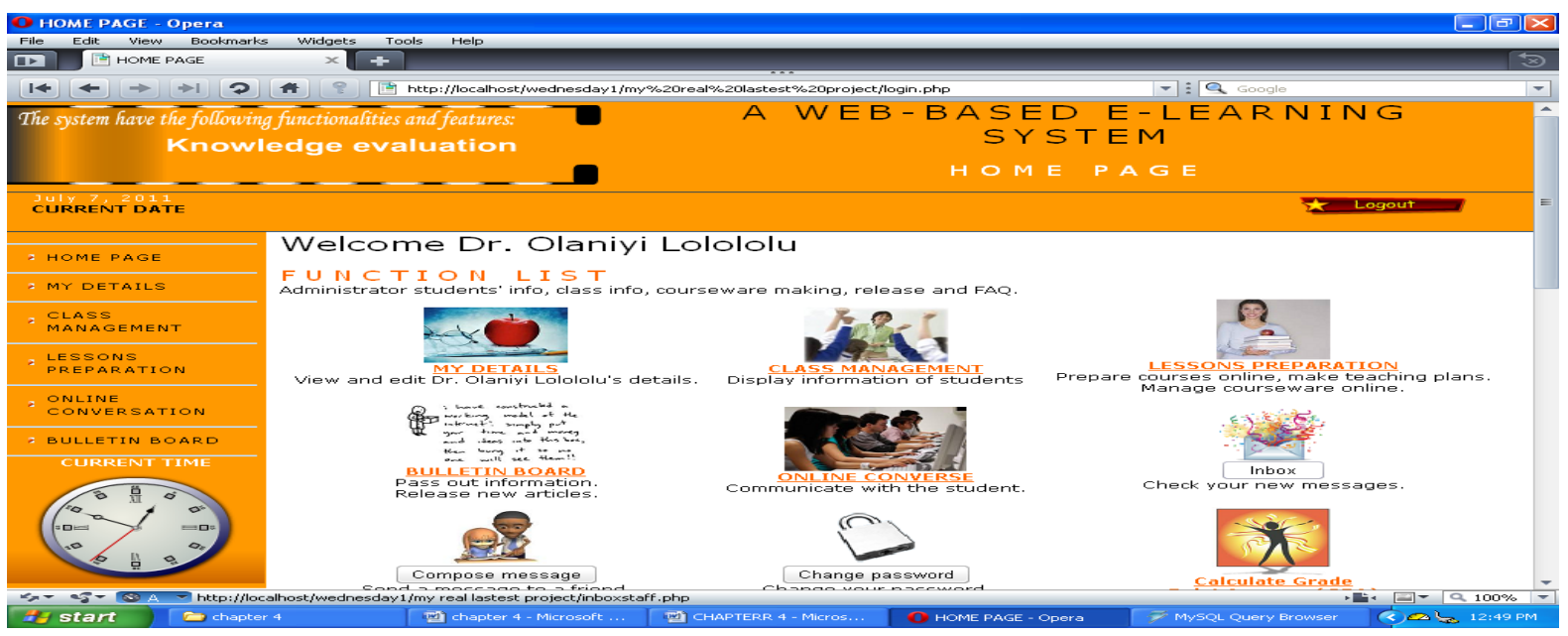

Figure 6. Staff home page. 


\subsubsection{The Bulleting Board}

The bulletin board (see Figure 9) allows you to check information and general announcements within the system. Staffs are capable of adding announcements.

\subsubsection{Online Conversation}

Here, staffs and students can express their feelings and post comments which will be seen by anyone in the system (see Figure 10).

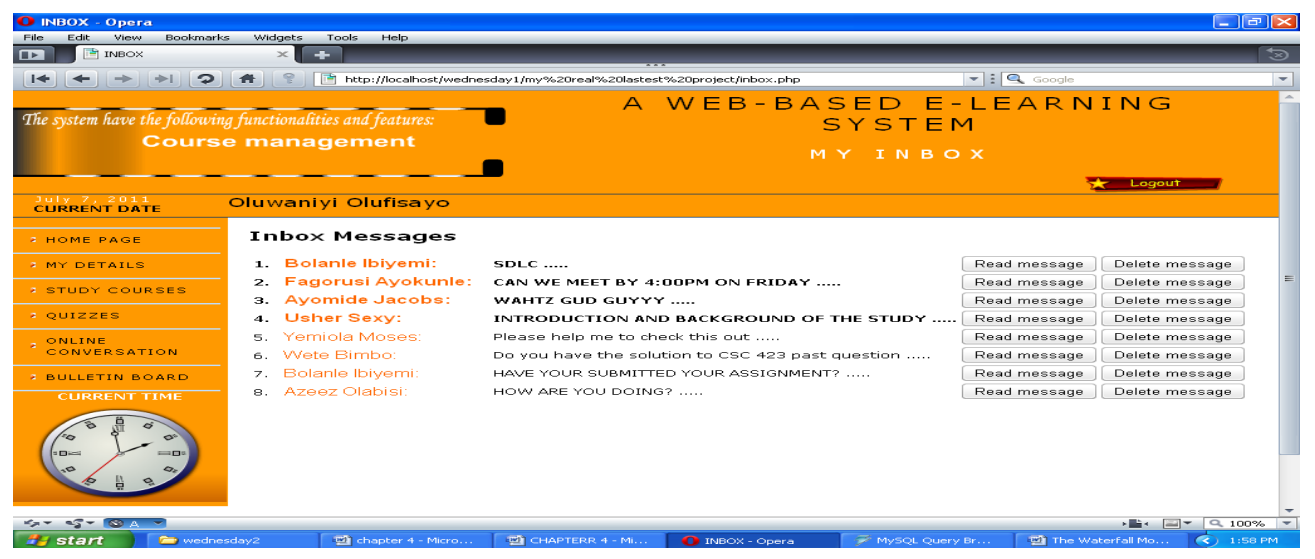

Figure 7. Inbox page.

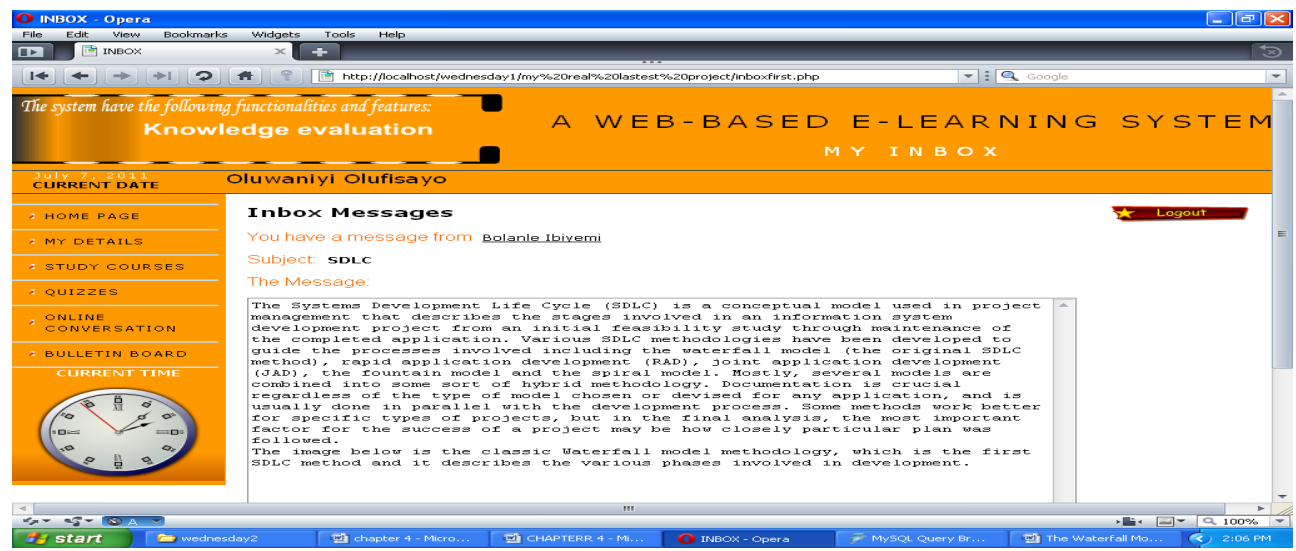

Figure 8. Inbox (message).

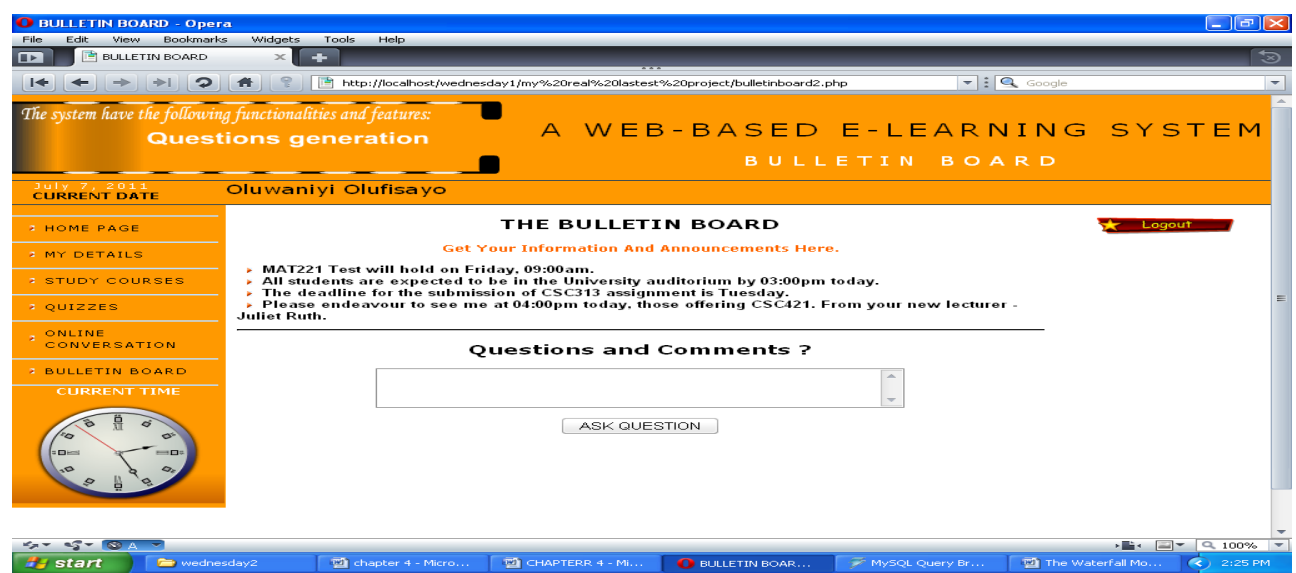

Figure 9. The bulletin board. 


\subsubsection{Select Course}

This page (see Figure 11) allows a student to select a particular course he/she wishes to study from a drop down list.

\subsubsection{Study Course Page}

This page (see Figure 12) allows a student to view full lesson/course simply by clicking on any button on the page. Students can submit assignments, take practice questions and quizzes, view past questions and answers and watch videos.

\subsubsection{Grade Point Average Page}

Students, staffs and administrator can calculate grade point average on this page (see Figure 13).

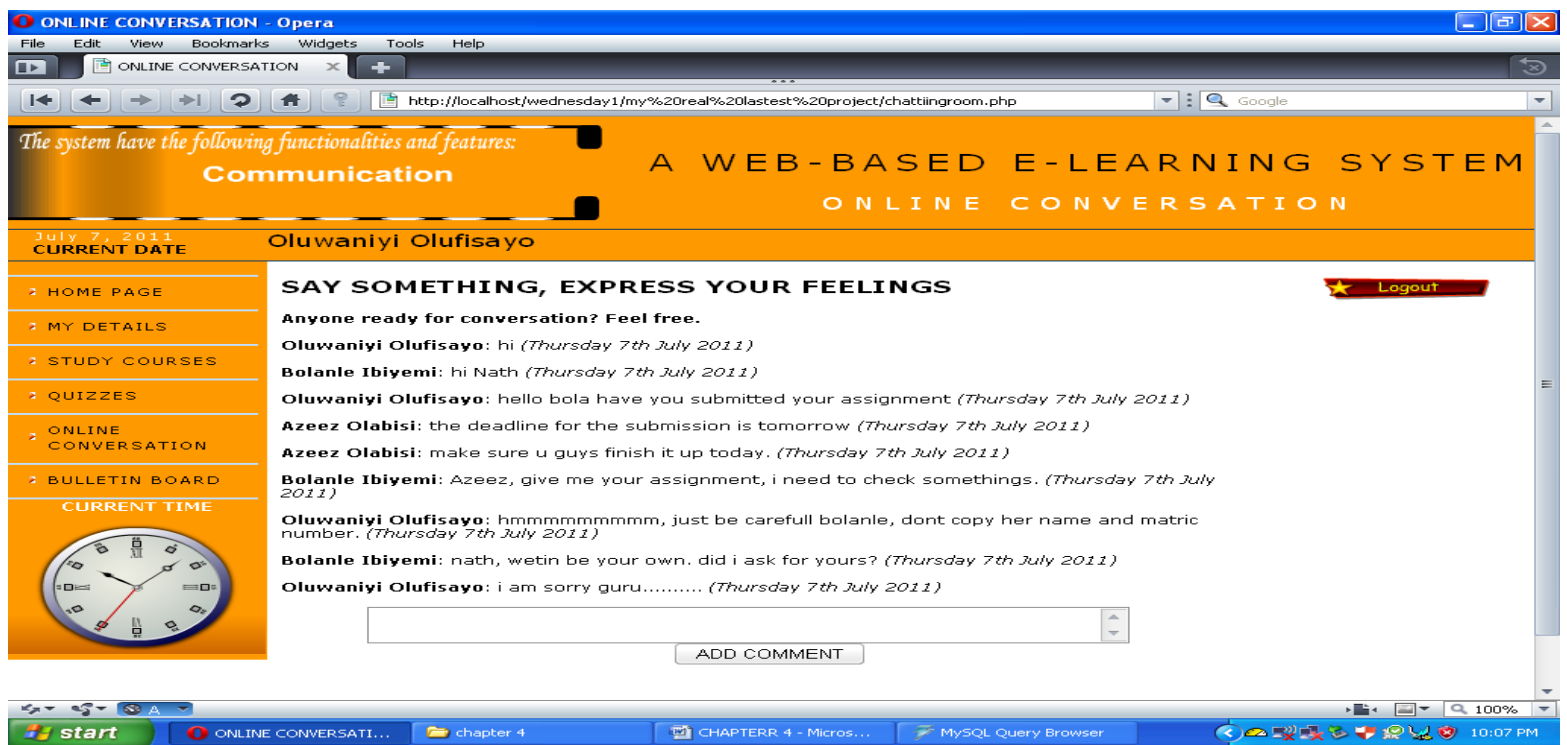

Figure 10. Online conversation.

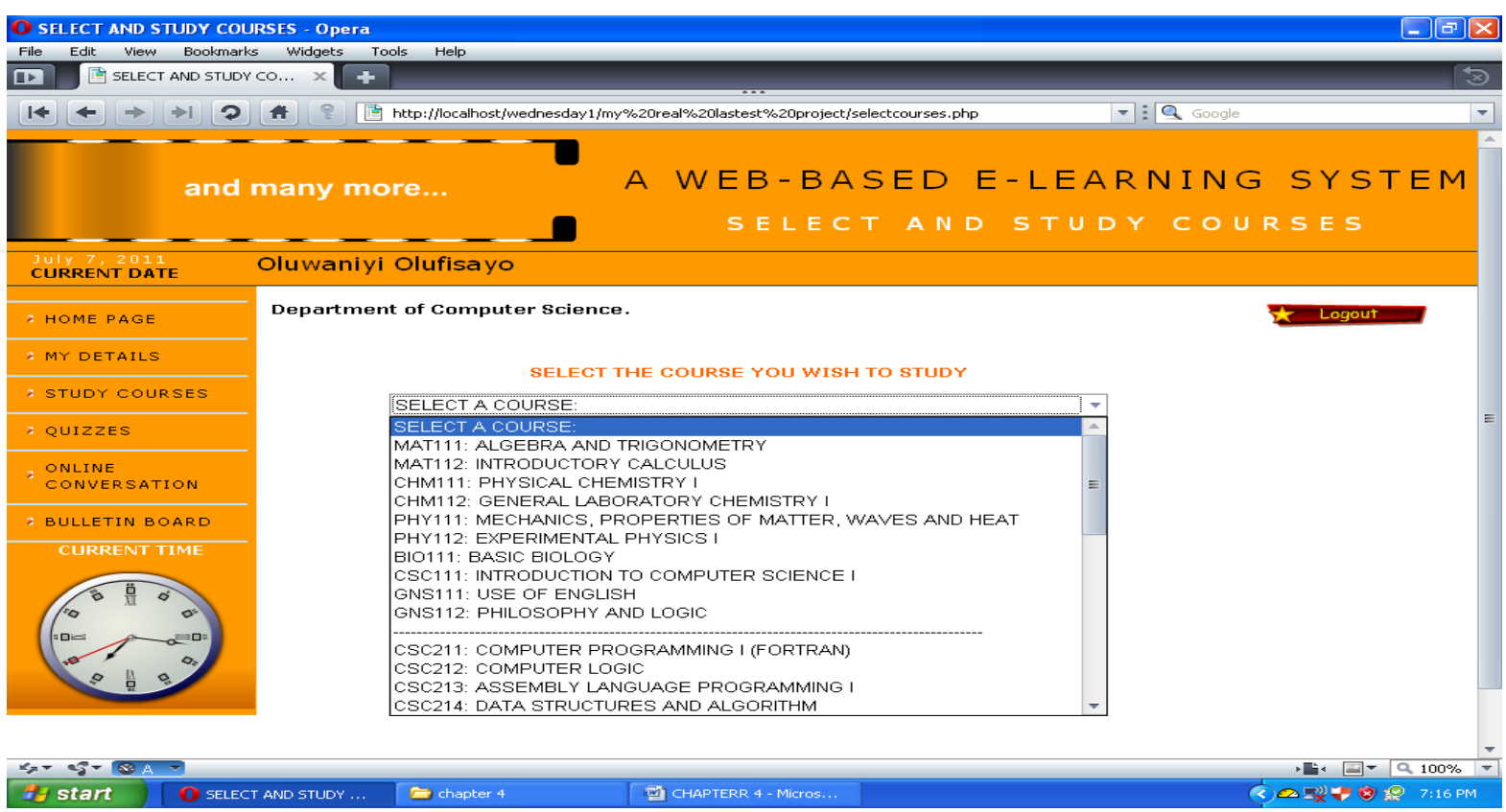

Figure 11. Select course. 


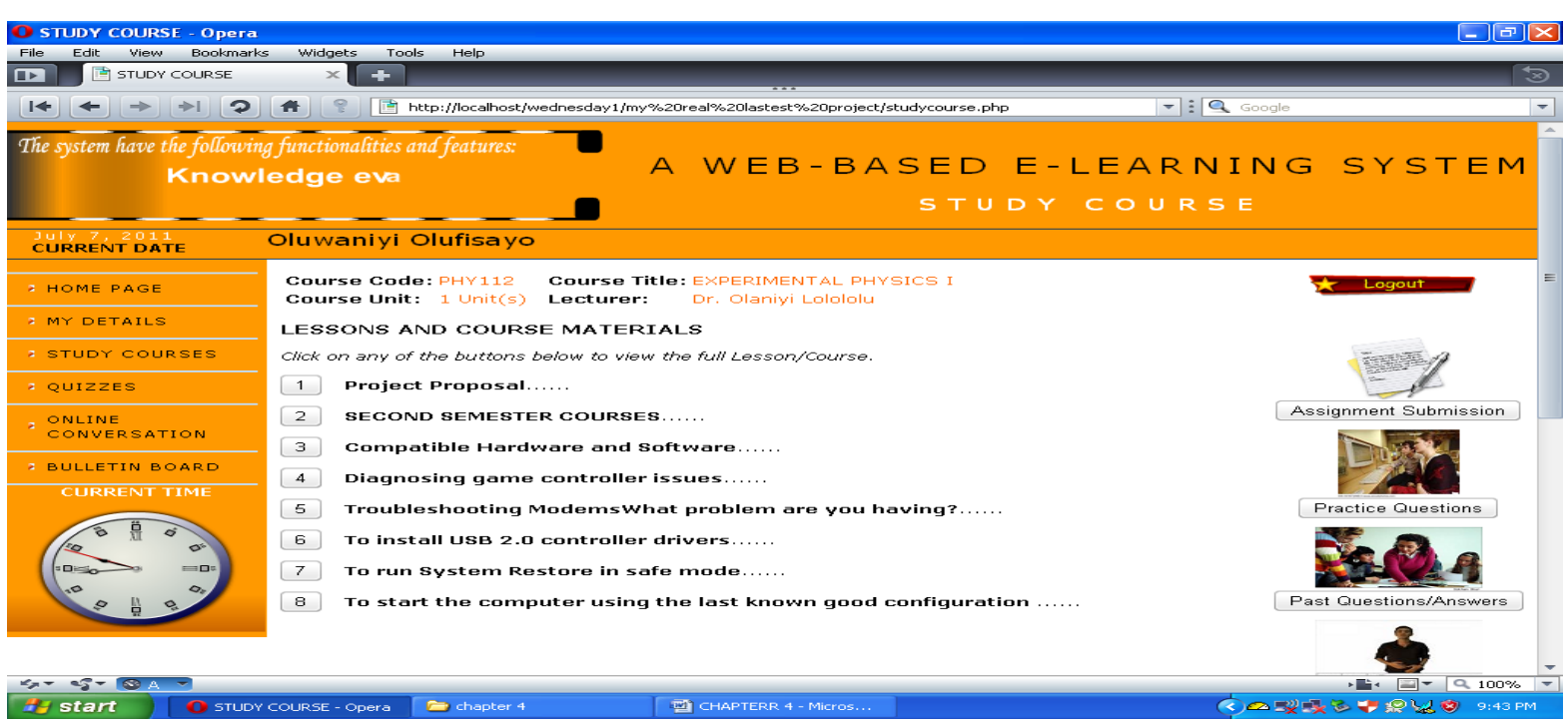

Figure 12. Study course page.

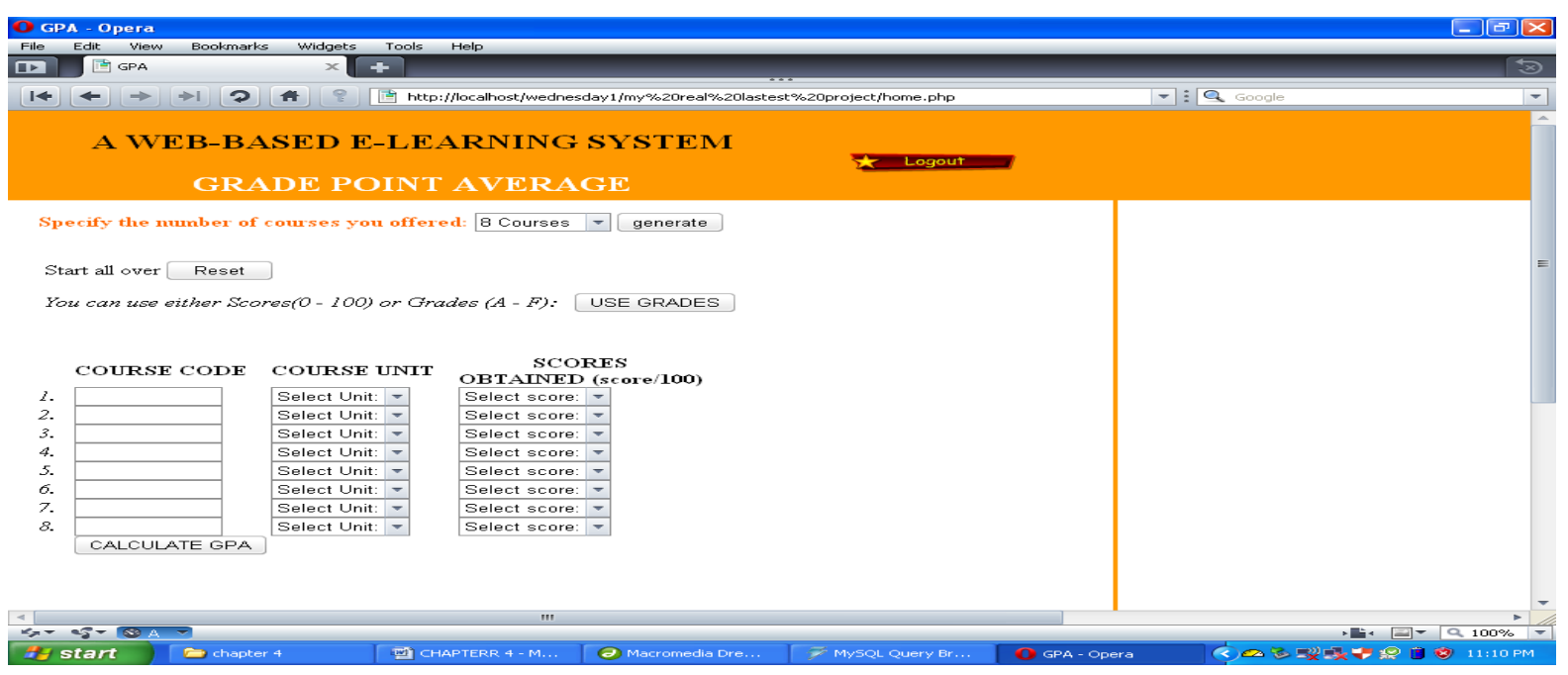

Figure 13. Grade point average page.

\subsubsection{Class Management Page}

On this page (see Figure 14) the details of students offering a particular course is displayed, their names, matric number, department, level, username and the overall percentage score in tests/quizzes for a particular course.

\subsubsection{Administrators Page}

This page (see Figure 15) shows the main page of an administrator. On the page the administrator can set the current semester and academic session, add a new course, add registration key, view all valid registration keys and calculate grade point average (GPA).

\section{Conclusion and Recommendation}

\subsection{Conclusion}

The web-based asynchronous e-learning system will reduce the constraints of the classical learning system and save time and resources. Course lecturers can set their courses, tests and quizzes at their convenient time and can track the activities and performance of their students and guide them to acquire knowledge without being obliged to be physically present on the institution campus. This system is no doubt a solution to the constraints of 


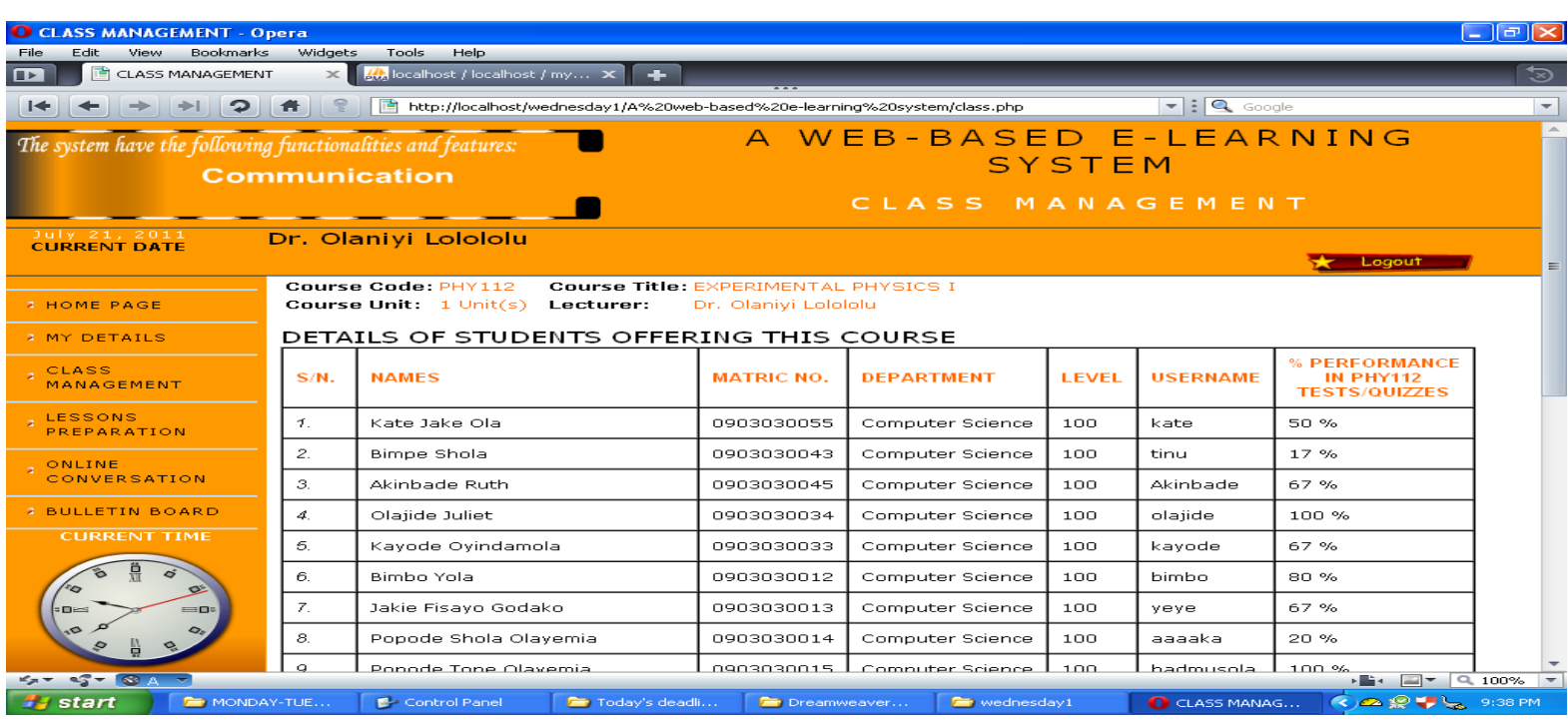

Figure 14. Class management page.

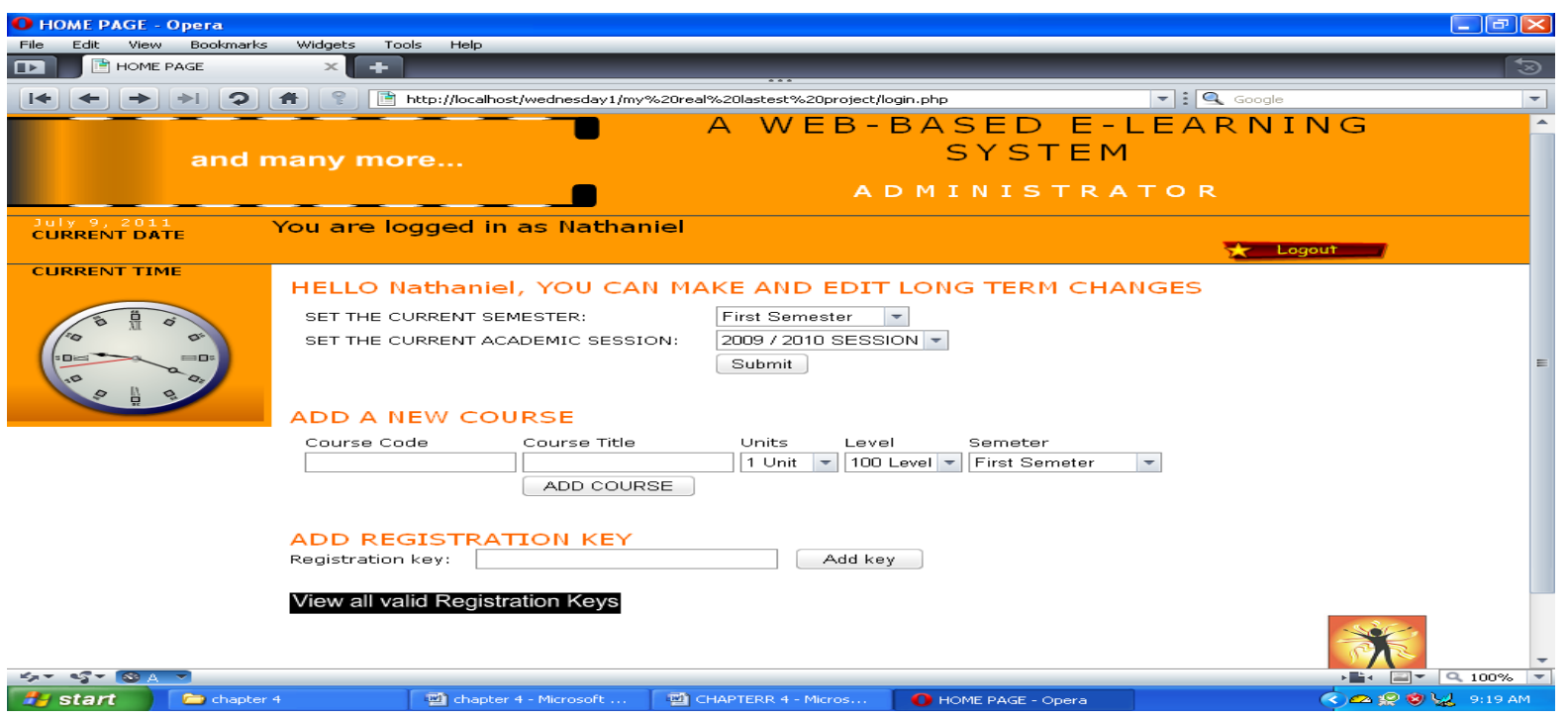

Figure 15. Administrator page.

the classical learning system.

\subsection{Recommendation}

Educational institutions need to be awaked and embrace e-learning system in order to meet the growing need for education and technology. It would be worthwhile if education agencies collaborate with institutions to fund researches on e-learning and virtual classroom instead of spending money in constructing classrooms that will never be adequate for the ever-increasing population. Government should to come up with legislations and guidelines for the implementation of e-learning and virtual classrooms so that the certificates obtained through e-learning can be universally acceptable.

\section{References}

[1] Ramim, M. and Levy, Y. (2006) Securing e-Learning Systems: A Case of Insider Cyber Attacks and Novice ITmanagement in a Small University. Journal of Cases on Information Technology, 8, 24-34. http://dx.doi.org/10.4018/jcit.2006100103 
[2] Alias, N.A. and Zainuddin, A.M. (2005) Innovation for Better Teaching and Learning: Adopting the Learning Management System. Malaysian Online Journal of Instructional Technology, 2, 27-40.

[3] Karim, M.R.A. and Hashim, Y. (2004) The Experience of e-Learning Implementation at the Universiti Pendidikan Sultan Idris, Malaysia. Malasian Online Journal of Instructional Technology, 1, 50-59.

[4] Nichols, M. (2003) A Theory for E-Learning. Journal of Educational Technology and Society, 6, 1-10.

[5] Nor, A. and Ahmed, M. (2005) Innovation for Better Teaching and Learning: Adopting the Learning Management System. Malaysian Online Journal of Instructional Technology, 2, 27-40.

[6] Ajayi, I.A. (2008) Towards Effective Use of Information and Communication Technology for Teaching in Nigerian Colleges of Education. Asian Journal of Information Technology, 7, 210-214.

[7] Zhang, D., Zhou, L., BrIggs, R. and Nunamaker, J. (2006) Instructional Video in e-Learning: Assessing the Impact of Interactive Video on Learning Effectiveness. Information and Management, 43, 15-27. http://dx.doi.org/10.1016/j.im.2005.01.004

[8] Douglas, I. (2001) Instructional Design Based on Reusable Learning Object: Applying Lessons of Object-Oriented Software Engineering to Learning System Design. Proceeding of ASEE/IEEE Frontiers in Education Conference, Reno, 2001, Vol. 3: F4E1-F4E5. http://dx.doi.org/10.1109/fie.2001.963968

[9] Wood, R. and Ashfield, J. (2008) The Use of the Interactive Whiteboard for Creative Teaching and Learning in Literacy and Mathematics: A Case Study. British Journal of Educational Technology, 39, 84-96.

[10] Evans, C. and Fan, J.P., (2002) Lifelong Learning through the Virtual University. Campus-Wide Information Systems, 19, 127-134. http://dx.doi.org/10.1108/10650740210438810

[11] Leonard, B.., Akio, K., Arjan, D. and Giuseppe, D.M. (2006) A Web-Based e-Learning System for Increasing Study Efficiency by Stimulating Learner's Motivation. Published Online: 14 November 2006.

[12] Kibble, J.D. (2007) Effective Use of Course Management Systems to Enhance Student Learning: Experimental Biology 2007. Adv. Physiology Education, 31, 377-379. http://dx.doi.org/10.1152/advan.00064.2007

[13] Hosam, F.E., Ahmad, M.H., Jehad, M.A., Fayed, F.M.G. and Samir, A.E. (2006) A Web-Based E-Learning System Experiment. International Journal of Computing and Information Sciences, 4.

[14] Teh, G.P.L. (1999) Assessing Student Perceptions of Internet-Based Online Learning Environment. International Journal of Instructional Media, 26, 397-402.

[15] Lee-Post, A. (2009) E-Learning Success Model: An Information Systems Perspective. Electronic Journal of e-Learning, 7, 61-70.

[16] Leonard, B., Akio, K., Arjan, D. and Giuseppe, D.M. (2006) A Web-Based e-Learning System for Increasing Study Efficiency by Stimulating Learner’s Motivation. Published Online: 14 November 2006.

[17] Al-Adwan, A. and Smedly, J. (2012) Implementing E-Learning in the Jordanian Higher Education System: Factors Affecting Impact. International Journal of Education and Development using Information and Communication Technology (IJEDICT), 8, 121-135.

[18] Trentin, G. (2006) The Xanadu Project: Training Faculty in the Use of Information and Communication Technology for University Teaching. Journal of Computer Assisted Learning, 22, 182-196. http://dx.doi.org/10.1111/j.1365-2729.2006.00168.x

[19] Toomey, R., Priestly, I., Norman, A. and Mahony, G.B. (1998) Effective Teaching and Learning in a Simulated Environment: A Higher Education Case Study. Journal of Hospitality \& Tourism Education, 10, 28-32. http://dx.doi.org/10.1080/10963758.1998.10685194

[20] Obasa, A.I., Eludire, A.A. and Isaac, M. (2011) The Architectural Design of an Integrated Virtual Classroom System. Research Journal of Information Technology, 3, 43-48.

[21] Mahanta, D. and Ahmed, M. (2012) E-Learning Objectives, Methodologies, Tools and Its Limitation. International Journal of Innovative Technology and Exploring Engineering (IJITEE), 2, 46-51.

[22] Arkorful, V. and Abaidoo, N. (2014) The Role of e-Learning, the Advantages and Disadvantages of Its Adoption in Higher Education. International Journal of Education and Research, 2, 397-410.

[23] Yannis, P. (2004) An Approach for Managing the Evolution of Web-Based Educational Applications. International Journal of Web Engineering and Technology, 1, 148. 